\section{(- OPEN ACCESS}

\title{
Effects of occupational exposure to respirable quartz dust on acute myocardial infarction
}

\author{
Johannes Gellissen, Dagmar Pattloch, Matthias Möhner ${ }^{\circledR}$
}

\begin{abstract}
- Additional material is published online only. To view please visit the journal online (http://dx.doi.org/10.1136/ oemed-2018-105540).
\end{abstract}

Work and Health, Federal Institute for Occupational Safety and Health, Berlin, Germany

\section{Correspondence to}

Dr Matthias Möhner, Work and Health, Federal Institute for Occupational Safety and Health, Berlin 10317, Germany;

Moehner.Matthias@baua. bund.de

Received 19 October 2018 Revised 14 March 2019 Accepted 24 March 2019 Published Online First 22 April 2019

\begin{abstract}
Objectives The aim of this study is to investigate the effects of occupational exposure to respirable quartz (RQ) on first acute myocardial infarction (AMI). RQ causes pulmonary diseases like silicosis and has also been linked to cardiovascular diseases. Inflammation is hypothesised as the underlying pathway.

Methods We performed a 1:3 matched case-control study nested in a cohort of male uranium miners. We included cases (identified from hospital records and validated according to WHO criteria) who had suffered their first AMI while still employed and $<65$ years of age. Controls were matched by date of birth and Wismut recruitment era. RQ exposure was derived from a jobexposure matrix. We performed a conditional logistic regression adjusted for smoking, metabolic syndrome and baseline erythrocyte sedimentation rate. Subgroups by date of birth and Wismut recruitment era were analysed to minimise the impact of pre-exposures. Results The study base comprised 292 matched sets. The cumulative exposure ranged from 0 to $38.9 \mathrm{mg} /$ $\mathrm{m}^{3}$-years RQ. The adjusted OR of the highest RQ tertile (>14.62 mg/m $/ \mathrm{m}^{3}$-years) was 1.27 (95\% Cl 0.82 to 1.98$)$. However, for miners born after 1928 and hired in the earliest recruitment era (1946-1954), a significantly elevated risk was seen in the highest $\mathrm{RQ}$ tertile (OR=6.47 [95\% Cl 1.33 to 31.5]; 50 matched sets). Conclusions An impact of quartz dust on first AMI was observed only in a small subgroup that had virtually no pre-exposure to RQ. Further studies on the basis of complete occupational history are required to substantiate this finding.
\end{abstract}

\section{INTRODUCTION}

Respirable quartz (RQ) has long been known to cause silicosis. In 1997, the International Agency for Research on Cancer (IARC) determined that crystalline silica causes lung cancer. Both silicosis and lung cancer are believed to result from the strong inflammatory response that silica evokes in the lung. ${ }^{1}$ Furthermore, other conditions like chronic obstructive pulmonary disease ${ }^{2}$ and cardiovascular disease $^{3}$ have been associated with RQ. The exact biological mechanisms linking exposure to RQ with cardiovascular disease are still unclear.

Potential mechanisms discussed in the literature include systemic inflammation following primary inflammation of the lungs. ${ }^{4}$ There is growing evidence that inflammation is a key regulatory process in the pathophysiology of atherosclerosis. ${ }^{5}$ A cohort study demonstrated that the erythrocyte sedimentation rate (ESR) is a long-term

\section{Key messages}

What is already known about this subject?

- Exposure to respirable quartz (RQ) dust has been linked to cardiovascular disease.

- The findings for an association between RQ and coronary heart disease are inconsistent, and except for one study are based on mortality only.

What are the new findings?

- This nested case-control study of German uranium miners suggests that the risk of first acute myocardial infarction (AMI) might increase with RQ exposure.

- This observation is confined to a subgroup of miners who gathered a large amount of exposure as young adults and were then followed up for a long time.

- The analysis of other subgroups was hampered by unquantified pre-exposure or insufficient follow-up time.

How might this impact on policy or clinical practice in the foreseeable future?

- Given that high occupational exposure to RQ is still widespread in large parts of the world and that it causes a number of diseases, efforts to reduce such exposure need to be intensified.

- The list of diseases caused by RQ may possibly need to be expanded to include myocardial infarction.

- However, the impact of RQ on AMI needs to be quantified more precisely by means of largescale studies with information on the complete occupational history.

independent predictor of coronary heart disease. ${ }^{7}$ Taken together, RQ seems to be a first-rate candidate to cause inflammation-mediated acute myocardial infarction (AMI). However, the number of studies investigating the impact of occupational RQ dust on the AMI-risk yields inconsistent results. ${ }^{4}$

Some cohort studies report elevated risks of coronary heart disease mortality by RQ, ${ }^{38}$ yet this has not been confirmed by other cohort studies.' The same applies to case-control studies. ${ }^{10}$ Casecontrol studies from Sweden ${ }^{11}$ and South Africa ${ }^{12}$ reported elevated risks but a later case-control study nested in a South African gold miner cohort did not confirm this. ${ }^{13}$ All studies cited, except for one ${ }^{11}$ investigated cardiovascular mortality. Besides the questionable validity of certified causes 


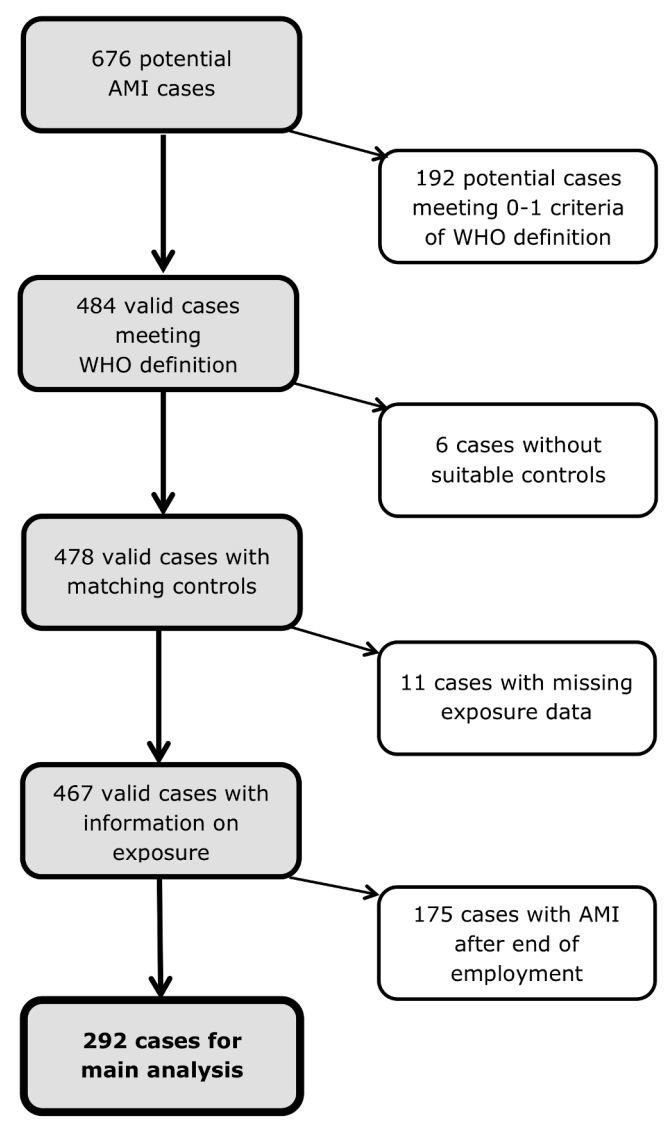

Figure 1 Flowchart of the inclusion process of cases. AMI, acute myocardial infarction.

of death, this definition of the endpoint does not differentiate between first and recurrent AMI events and obscures the time of onset. The time lag between first AMI and death may be considerable, thus shifting the focus of the study to older age. The temporal reference to occupational dust may lose precision and, moreover, be biased by job changes due to earlier cardiovascular events (eg, angina pectoris). Therefore, we investigated the impact of RQ on the first AMI in a nested case-control study.

\section{METHODS}

\section{Study population}

This study is nested in the German Uranium Miners cohort study (Wismut cohort) run by the Federal Office for Radiation Protection (BfS). The cohort comprises a sample of approximately 60000 employees who worked in uranium ore mining between 1946 and $1990 .{ }^{14}$ The cohort was stratified according to the period of hiring (1946-1954, 1955-1970, 1971-1989, subsequently denoted as subcohorts A, B and C). These strata represents different mining conditions in terms of exposure to radiation and dust, with different sampling probabilities for the strata, too. ${ }^{15}$

In parallel, the Federal Institute for Occupational Safety and Health (BAuA) runs the health data archives Wismut (GDAW), which provide 12000 linear metres of medical records and radiography of former uranium miners, including medical records on health surveillance, hospital discharge diagnosis and occupational diseases. All hospitalisations of the cohort were digitised. This file comprises 114000 hospitalisations in nearly 28000 ever hospitalised patients. The hospital discharge diagnoses are coded in ICD-10. We searched for ICD-10: I21, I22, I25.2, I29.9+ plaintext and thus identified 676 potential first AMI cases. To validate these, we reviewed inpatient and outpatient medical records.

We applied the 1979 WHO definition of myocardial infarction, which requires at least two out of three criteria (clinical symptoms, ECG evaluation and laboratory values) to be fulfilled. We then excluded (1) 6 cases where no suitable controls were available, (2) 11 cases lacking exposure data, (3) 175 cases with AMI dated after leaving the company. The latter restriction was necessary because the information on exposure and outcome can be assumed to be complete only for the period of Wismut-employment. Controls were individually matched at a ratio of $3: 1$ by date of birth ( \pm 1 year) and period of hiring. The event date of the case defines the index date for the respective case-control set. At the index date, all controls were as old as the corresponding case, had been employed at the Wismut company, had benefited from the company's health system and were free of AMI.

\section{Classic risk factors and markers of systemic inflammation}

Information on classic risk factors of atherosclerosis, that is, smoking habits, blood pressure, cholesterol and blood glucose level, and on ESR as a marker of systemic inflammation were collected from medical records covering the period of commencement of employment until the index date. The presence of hypertension, hypercholesterolaemia and diabetes was presumed if either a medical diagnosis was given as a plain text, or a respective medication or at least three elevated laboratory values were ascertained (thresholds: hypertension 160/100 $\mathrm{mm} \mathrm{Hg}$, hypercholesterolaemia $\geq 6.2 \mathrm{mmol} / \mathrm{L}$, diabetes $\geq 7.0 \mathrm{mmol} / \mathrm{L}$ ). The diagnoses and treatment decisions were based on the state of knowledge during the study period 1950-1989 applying thresholds at that time. Therefore, we did not choose current thresholds for the analysis. Information on classic risk factors 5 years prior to index date were omitted to avoid a lead time bias, that is, the inflated chance to detect a case's risk factors because of early cardiovascular symptoms. We defined the metabolic syndrome by the presence of $\geq 3$ out of 4 criteria (obesity, hypertension, diabetes and hypercholesterolaemia), approximating the International Diabetes Federation (IDF) metabolic syndrome consensus definition. ${ }^{16}{ }^{17}$ ESR was considered elevated for a 1-hour value $>10 \mathrm{~mm}$ and a 2 -hour value $>20 \mathrm{~mm}$.

\section{Exposure assessment}

The BfS provided exposure measures per person and year that combine the job-exposure matrix ${ }^{18}$ with the individual job history. The cumulative RQ exposure is given in $\mathrm{mg} / \mathrm{m}^{3}$-years, which is defined as an exposure to $1 \mathrm{mg} / \mathrm{m}^{3}$ over 220 shifts of 8 hours each. ${ }^{14}$ The individual cumulative RQ exposure was calculated omitting the 5 years preceding the index date. We thus aimed to avoid a healthy-worker effect, which can arise if early cardiovascular symptoms cause a change from an exposed to an unexposed job. The extent of exposure prior to the Wismut employment cannot be quantified, even if some qualitative binary information on pre-exposure is available as a part of the personnel index card accompanying the preventive medical examinations. Our first concern was pre-exposure during military service, internment (for example, as a prisoner of war), or (pre-war) coal mining. To manage this, we created a further binary categorisation whether a subject was older or younger than 16 years at the end of World War II (born before or after 8 May 1929, subsequently denoted as early and late birth cohorts). Our second concern was that, in general, every employee who entered the company beyond young adulthood may have gathered occupational pre-exposure beforehand. The Wismut 
Table 1 Description of the study population

\begin{tabular}{|c|c|c|c|c|c|c|}
\hline \multirow[b]{2}{*}{ Date of birth } & \multicolumn{2}{|c|}{$\begin{array}{l}\text { Before } 08.05 .1929 \\
\text { (early birth cohorts) }\end{array}$} & \multicolumn{2}{|c|}{$\begin{array}{l}\text { After } 08.05 .1929 \\
\text { (late birth cohorts) }\end{array}$} & \multicolumn{2}{|l|}{ Total } \\
\hline & Cases & Controls & Cases & Controls & Cases & Controls \\
\hline $\mathrm{n}$ & 182 & 542 & 110 & 330 & 292 & 872 \\
\hline Year of birth, mean (SD) & $1919(7.3)$ & $1919(7.3)$ & $1935(5.5)$ & $1935(5.5)$ & $1925(10.0)$ & $1925(10.0)$ \\
\hline Year of hiring, mean (SD) & $1950(4.3)$ & $1950(4.3)$ & 1957 (8.6) & $1957(8.0)$ & $1953(7.0)$ & $1953(6.6)$ \\
\hline Age at hire, mean (SD) & $31.1(8.8)$ & $31.4(8.7)$ & $22.0(6.5)$ & $22.0(5.7)$ & $27.7(9.1)$ & $27.9(8.9)$ \\
\hline Age at index date ${ }^{*}$, mean (SD) & $55.2(5.8)$ & $55.3(5.7)$ & $47.9(6.6)$ & $47.9(6.6)$ & $52.5(7.1)$ & $52.5(7.0)$ \\
\hline Time since hire, mean (SD) & $24.1(8.7)$ & $23.9(8.7)$ & $25.9(9.0)$ & $26.0(8.5)$ & $24.8(8.9)$ & $24.7(8.7)$ \\
\hline \multicolumn{7}{|l|}{ Last smoking status, $\mathrm{n}(\%)$} \\
\hline Non-smoker & $14(7.7)$ & $116(21.4)$ & $6(5.5)$ & $81(24.5)$ & $20(6.8)$ & $197(22.6)$ \\
\hline Ex-smoker & $28(15.4)$ & $68(12.5)$ & $13(11.8)$ & $48(14.5)$ & $41(14.0)$ & $116(13.3)$ \\
\hline Smoker & $123(67.6)$ & $245(45.2)$ & $89(80.9)$ & $164(49.7)$ & $212(72.6)$ & $409(46.9)$ \\
\hline Unknown & $17(9.3)$ & $113(20.8)$ & $2(1.8)$ & $37(11.2)$ & $19(6.5)$ & $150(17.2)$ \\
\hline Diabetes mellitust, $\mathrm{n}(\%)$ & $15(8.2)$ & $7(1.3)$ & $12(10.9)$ & $8(2.4)$ & $27(9.3)$ & $15(1.7)$ \\
\hline Hypertensiont, $\mathrm{n}(\%)$ & $57(31.3)$ & $108(19.9)$ & 39 (35.5) & $83(25.2)$ & $96(32.9)$ & $191(21.9)$ \\
\hline Hypercholesterolaemiat, $\mathrm{n}(\%)$ & $3(1.6)$ & $8(1.5)$ & $13(11.8)$ & $5(1.5)$ & $16(5.5)$ & $13(1.5)$ \\
\hline Obesity¥, n (\%) & $17(9.3)$ & $59(10.9)$ & $21(19.1)$ & $44(13.3)$ & $38(13.0)$ & $103(11.8)$ \\
\hline \multicolumn{7}{|c|}{ Erythocyte sedimentation rate, earliest/baseline measure } \\
\hline Elevated $\S, n(\%)$ & $43(24.9)$ & $86(16.2)$ & $21(19.1)$ & $30(9.1)$ & $64(21.9)$ & $116(13.3)$ \\
\hline 1 hour, mean (SD) & $8.6(12.0)$ & $6.8(8.6)$ & $7.3(10.1)$ & $5.9(11.1)$ & $8.1(11.3)$ & $6.5(9.6)$ \\
\hline 2 hours, mean (SD) & $17.8(18.6)$ & $14.8(14.5)$ & $16.3(17.0)$ & $12.6(15.0)$ & $17.2(18.0)$ & $14.0(14.7)$ \\
\hline Metabolic syndromeף, n (\%) & $7(3.8)$ & $5(0.9)$ & $7(6.4)$ & $6(1.8)$ & $14(4.8)$ & $11(1.3)$ \\
\hline Cumulative $\mathrm{RQ}^{* *}$ (mg/m -years), mean (SD) & $12.94(8.91)$ & $13.18(9.77)$ & $9.12(8.68)$ & $8.42(8.23)$ & $11.5(9.00)$ & $11.38(9.50)$ \\
\hline
\end{tabular}

*Date of cases' diagnosis of first acute myocardial infarction, date when the control was the same age as the case at his diagnosis.

$\dagger$ Ascertained by diagnosis, medication or measured $\geq 3$ times ( 5 years prior to the index date).

$\ddagger$ Body mass index $\geq 30$ measured $\geq 3$ times ( 5 years prior to the index date).

$\S$ Elevated: 1 -hour value $>10 \mathrm{~mm}$ and 2 -hour value $>20 \mathrm{~mm}$.

$\eta \geq 3$ criteria fulfilled 5 years prior to the index date (obesity, hypertension, diabetes, hypercholesterolaemia).

** Until 5 years prior to the index date.

$\mathrm{RQ}$, respirable quartz.

company hired experienced coal miners in the 1960s (subcohort B) to establish a permanent staff. ${ }^{19}$ With regard to the study objective, pre-exposure is less harmful if it is small compared with relatively high measured exposure. Hence, we investigated the six subgroups, defined by their birth cohort (early, late) and period of hiring ( $A, B$ and $C$ ), to find out a subgroup with a chance of occupational pre-exposure to RQ as low as possible.

\section{Statistical analysis}

To account for different time-related changes a tight matching was used, taking into account date of birth and period of hiring. Hence, a matched analysis was required. ORs and two-sided $95 \%$ CIs were calculated by conditional logistic regression. ${ }^{20}$ Cumulative exposure was categorised into tertiles to account for non-linearity in a possible exposure-response relationship. In addition, calculations were also made assuming a linear or log-linear exposure-response relationship. The model fit was assessed by means of a corresponding likelihood-ratio test, as well as by Akaike's information criterion (AIC). All statistical analyses were performed using the STATA software package V.15. ${ }^{21}$ Smoking, the baseline ESR and the metabolic syndrome ${ }^{22}$ (combined from hypertension, diabetes, hypercholesterolaemia and obesity) were considered as potential confounders.

To better control the impact of the confounding variables on the RQ-related risk estimates, we applied three models and calculated: the crude OR, the OR adjusted for the potential confounders smoking and baseline ESR, and finally the OR with additional adjustment for the metabolic syndrome as a suspected mediator.

\section{RESULTS}

Six hundred seventy six potential cases of AMI were identified from hospital discharge diagnoses, resulting in 484 valid cases according to the 1979 WHO definition of myocardial infarction. Reviewing the complete medical records ensured that only primary events of myocardial infarction were captured.

Exclusion of 192 cases for various reasons resulted in 292 cases for the main analysis (figure 1). These were matched with 872 controls, that is, most cases matched 3 controls. The date of birth of the controls differed by 4.4 days on average (maximum $=246$ days) from the date of birth of the respective case. Table 1 shows the main characteristics of the study population by the two birth-cohort strata. The study population was born between 1902 and 1960 and commenced employment between 1946 and 1986. The subgroups differ considerably from each other. Miners from subcohort A had on average more than 35 -fold cumulative exposure in comparison to miners from subcohort $\mathrm{C}$ (table 2). The age at hire also differs considerably between the six subgroups formed by the birth cohorts and the period of hiring. The lowest average age at hire was observed for the subgroup of the late birth cohort from subcohort A. Hence, the impact of relevant pre-exposures should be negligible in this subgroup. Moreover, the period between hire and index date covers on average more than 30 years in this subgroup and is therefore significantly longer in comparison to all other subgroups.

RQ exposure strongly depends on calendar time (figure 2). Within the study population, the median exposure concentration peaked in 1952 with $1.6 \mathrm{mg} / \mathrm{m}^{3}$. It then decreased to 0.3 in 1963 and further to 0.03 in 1970. 
Table 2 Description of the study population by subcohorts and date of birth

\begin{tabular}{|c|c|c|c|c|c|c|c|c|c|}
\hline \multirow{2}{*}{\multicolumn{2}{|c|}{ Date of birth }} & \multicolumn{2}{|c|}{$\begin{array}{l}\text { Subcohort A } \\
\text { (Hired 1946-1954) }\end{array}$} & \multicolumn{2}{|c|}{$\begin{array}{l}\text { Subcohort B } \\
\text { (Hired 1955-1970) }\end{array}$} & \multicolumn{2}{|c|}{$\begin{array}{l}\text { Subcohort C } \\
\text { (Hired since 1971) }\end{array}$} & \multicolumn{2}{|l|}{ Total } \\
\hline & & Cases & Controls & Cases & Controls & Cases & Controls & Cases & Controls \\
\hline \multirow{11}{*}{$\begin{array}{l}\text { Before } \\
08.05 .1929\end{array}$} & Subjects (n) & 152 & 453 & 28 & 84 & 2 & 5 & 182 & 542 \\
\hline & Mean date of birth & 04.02 .1920 & 12.02 .1920 & 05.12.1917 & 30.01 .1918 & 17.09 .1926 & 07.07 .1926 & 01.11 .1919 & 11.11 .1919 \\
\hline & Mean age at hire (years) & 29.4 & 29.7 & 39.4 & 40.0 & 48.6 & 47.4 & 31.1 & 31.4 \\
\hline & Mean index date & 14.12.1974 & 02.02 .1975 & 25.01 .1975 & 03.04 .1975 & 11.03 .1983 & 16.09 .1983 & 23.01 .1975 & 13.03 .1975 \\
\hline & Mean age (years) & 54.9 & 55.0 & 57.1 & 57.2 & 56.6 & 57.2 & 55.2 & 55.3 \\
\hline & Mean time since hire (years) & 25.5 & 25.3 & 17.8 & 17.2 & 8.0 & 9.9 & 24.1 & 23.9 \\
\hline & Mean RQ exposure ( $\mathrm{mg} / \mathrm{m}^{3}$-years) & 14.63 & 14.92 & 4.67 & 4.54 & 0.10 & 0.16 & 12.94 & 13.18 \\
\hline & Silicosis, $n(\%)$ & $23(15.1)$ & $50(11.0)$ & $1(3.6)$ & $1(1.2)$ & $0(0.0)$ & $0(0.0)$ & $24(13.2)$ & $51(9.4)$ \\
\hline & Average latency to silicosis (years) & 15.7 & 16.6 & 12.2 & 1.6 & - & - & 15.6 & 16.3 \\
\hline & Pre-exposure to RQ*, n (\%) & $9(5.9)$ & $15(3.3)$ & $3(10.7)$ & $4(4.8)$ & $0(0.0)$ & $0(0.0)$ & $12(6.6)$ & $19(3.5)$ \\
\hline & Former coalmining ${ }^{*}, \mathrm{n}(\%)$ & $31(20.4)$ & $84(18.5)$ & $5(17.9)$ & $15(17.9)$ & $1(50.0)$ & $1(20.0)$ & $37(20.3)$ & $100(18.5)$ \\
\hline \multirow{11}{*}{$\begin{array}{l}\text { After } \\
\text { 08.05.1929 }\end{array}$} & Subjects (n) & 50 & 150 & 50 & 151 & 10 & 29 & 110 & 330 \\
\hline & Mean date of birth & 28.10 .1931 & 26.10 .1931 & 18.03.1937 & 27.03 .1937 & 14.03 .1942 & 22.05 .1942 & 20.03 .1935 & 24.03 .1935 \\
\hline & Mean age at hire (years) & 18.6 & 19.1 & 22.7 & 22.7 & 35.4 & 33.3 & 22.0 & 22.0 \\
\hline & Mean index date & 22.06 .1981 & 09.07.1981 & 08.05 .1984 & 22.05 .1984 & 24.11 .1984 & 27.01 .1985 & 03.02 .1983 & 22.02 .1983 \\
\hline & Mean age (years) & 49.7 & 49.7 & 47.1 & 47.2 & 42.7 & 42.7 & 47.9 & 47.9 \\
\hline & Mean time since hire (years) & 31.1 & 30.6 & 24.5 & 24.5 & 7.3 & 9.4 & 25.9 & 26.0 \\
\hline & Mean RQ exposure ( $\mathrm{mg} / \mathrm{m}^{3}$-years) & 16.35 & 14.19 & 3.65 & 4.23 & 0.32 & 0.42 & 9.12 & 8.42 \\
\hline & Silicosis, n (\%) & $5(10.0)$ & $12(8.0)$ & $0(0.0)$ & $1(0.7)$ & $0(0.0)$ & $0(0.0)$ & $5(4.5)$ & $13(3.9)$ \\
\hline & Average latency to silicosis (years) & 15.5 & 20.1 & - & 13.9 & - & - & 15.5 & 19.7 \\
\hline & Pre-exposure to $\mathrm{RQ}^{*}, \mathrm{n}(\%)$ & $2(4.0)$ & $7(4.7)$ & $3(6.0)$ & $6(4.0)$ & $0(0.0)$ & $2(6.9)$ & $5(4.5)$ & $15(4.5)$ \\
\hline & Former coalmining ${ }^{\star}, n(\%)$ & $5(10.0)$ & $17(11.3)$ & $7(14.0)$ & $16(10.6)$ & $0(0.0)$ & $4(13.8)$ & $12(10.9)$ & $37(11.2)$ \\
\hline \multirow[t]{11}{*}{ Total } & Subjects (n) & 202 & 603 & 78 & 235 & 12 & 34 & 292 & 872 \\
\hline & Mean date of birth & 31.12 .1922 & 10.01.1923 & 16.04.1930 & 22.05 .1930 & 14.08.1939 & 20.01 .1940 & 17.08 .1925 & 03.09 .1925 \\
\hline & Mean age at hire (years) & 26.7 & 27.0 & 28.7 & 28.9 & 37.6 & 35.4 & 27.7 & 27.9 \\
\hline & Mean index date & 25.07.1976 & 09.09 .1976 & 06.01 .1981 & 14.02 .1981 & 17.08 .1984 & 15.11.1984 & 01.02 .1978 & 16.03 .1978 \\
\hline & Mean age (years) & 53.6 & 53.7 & 50.7 & 50.7 & 45.0 & 44.8 & 52.5 & 52.5 \\
\hline & Mean time since hire (years) & 26.9 & 26.6 & 22.1 & 21.9 & 7.4 & 9.5 & 24.8 & 24.7 \\
\hline & Mean RQ exposure ( $\mathrm{mg} / \mathrm{m}^{3}$-years) & 15.06 & 14.74 & 4.02 & 4.34 & 0.28 & 0.38 & 11.50 & 11.38 \\
\hline & Silicosis, n (\%) & $28(13.9)$ & $62(10.3)$ & $1(1.3)$ & $2(0.9)$ & $0(0.0)$ & $0(0.0)$ & $29(9.9)$ & $64(7.3)$ \\
\hline & Average latency to silicosis (years) & 15.7 & 17.2 & 12.2 & 7.7 & - & - & 15.6 & 17.0 \\
\hline & Pre-exposure to $\mathrm{RQ}^{*}, \mathrm{n}(\%)$ & $11(5.4)$ & $22(3.6)$ & $6(7.7)$ & $10(4.3)$ & $0(0.0)$ & $2(5.9)$ & $17(5.8)$ & $34(3.9)$ \\
\hline & Former coalmining ${ }^{*}, n(\%)$ & $36(17.8)$ & $101(16.7)$ & $12(15.4)$ & $31(13.2)$ & $1(8.3)$ & $5(14.7)$ & $49(16.8)$ & $137(15.7)$ \\
\hline
\end{tabular}

*Based on qualitative information from records of preventive medical examinations.

$\mathrm{RQ}$, respirable quartz.

In view of the impact of potential pre-exposure, risk analyses were performed based on the entire database as well as for the late birth cohorts and, additionally, for the late birth cohorts

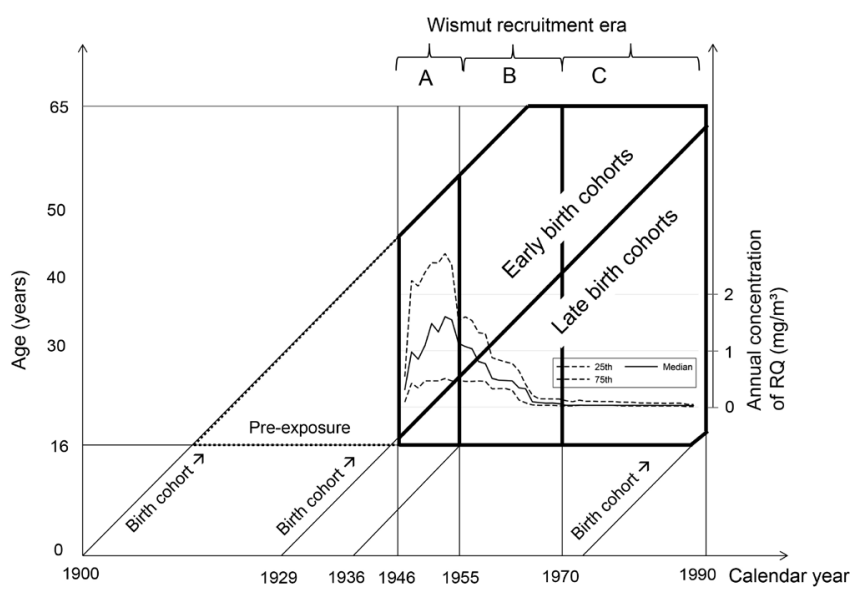

Figure 2 Lexis diagram of the study subjects with median and IQR of respirable quartz (RQ) concentration by calendar year (based on controls only). restricted to subcohort A, due to their low chance of considerable occupational pre-exposure to RQ.

Univariate risk estimates (online supplementary table S1) indicate strong associations of AMI with smoking and with the infrequent risk factors diabetes, the metabolic syndrome and hypercholesterolaemia.

We applied the categorised cumulative RQ exposure with the lowest RQ tertile as referent in the main analysis, where the tertiles were calculated based on all AMI cases. The analysis of the entire database does not reveal a clear relationship between RQ exposure and risk of AMI, even if the OR for the middle tertile is significantly elevated (table 3). Although the analysis restricted to the late birth cohort suggests such a relationship, the significance threshold is not exceeded even in the highest tertile. The analysis of the late birth cohorts from subcohort A, however, yields a significant increase in the risk of AMI with $\mathrm{OR}=6.47$ (95\%CI: 1.33 to 31.5 ) in the highest tertile.

We also included the exposure as a linear term instead of tertiles. While in the entire database an increased risk could not be observed ( $\mathrm{OR}=1.00$ [95\% CI 0.98 to 1.02 ] per $1 \mathrm{mg} /$ $\mathrm{m}^{3}$-year), it was $\mathrm{OR}=1.04$ (95\% CI 0.99 to $\left.1.09 ; \mathrm{p}=0.10\right)$ for the subgroup of late birth cohorts from subcohort A in the fully adjusted model. A much better model fit was achieved by a 
Table 3 ORs for the first acute myocardial infarction by cumulative exposure to respirable quartz (RQ)

\begin{tabular}{|c|c|c|c|c|c|c|c|c|c|c|}
\hline \multirow{2}{*}{$\begin{array}{l}\mathrm{RQ} \text { ( } \mathrm{mg} / \mathrm{m}^{3} \text {-years) } \\
\text { Inclusion of } \mathrm{RQ} \text { as }\end{array}$} & \multicolumn{3}{|c|}{ Entire database } & \multicolumn{3}{|c|}{ Late birth cohorts only* } & \multicolumn{4}{|c|}{ Late birth cohorts* from sub-cohort A only } \\
\hline & Cases & Controls & OR $(95 \% \mathrm{Cl})$ & Cases & Controls & OR $(95 \% \mathrm{Cl})$ & Cases & Controls & OR & $(95 \% \mathrm{Cl})$ \\
\hline \multicolumn{11}{|l|}{ Tertilest } \\
\hline$<5.74$ & 97 & 330 & 1.00 (referent) & 53 & 166 & 1.00 (referent) & 2 & 29 & 1.00 & (referent) \\
\hline 5.74 to $<14.62$ & 97 & 247 & 1.52 (1.02 to 2.25$)$ & 27 & 92 & $1.03(0.53$ to 1.99$)$ & 20 & 53 & 5.42 & (1.19 to 24.8$)$ \\
\hline$\geq 14.62$ & 98 & 295 & 1.32 (0.87 to 1.99$)$ & 30 & 72 & 1.59 (0.74 to 3.42$)$ & 28 & 68 & 6.36 & (1.37 to 29.6$)$ \\
\hline \multicolumn{11}{|l|}{ Tertilesł } \\
\hline$<5.74$ & 97 & 330 & 1.00 (referent) & 53 & 166 & 1.00 (referent) & 2 & 29 & 1.00 & (referent) \\
\hline 5.74 to $<14.62$ & 97 & 247 & 1.65 (1.09 to 2.51$)$ & 27 & 92 & 1.19 (0.56 to 2.51$)$ & 20 & 53 & 6.53 & (1.35 to 31.5$)$ \\
\hline$\geq 14.62$ & 98 & 295 & 1.25 (0.80 to 1.93$)$ & 30 & 72 & 1.58 (0.67 to 3.69$)$ & 28 & 68 & 6.55 & (1.35 to 31.8 ) \\
\hline \multicolumn{11}{|l|}{ Tertiles§ } \\
\hline$<5.74$ & 97 & 330 & 1.00 (referent) & 53 & 166 & 1.00 (referent) & 2 & 29 & 1.00 & (referent) \\
\hline 5.74 to $<14.62$ & 97 & 247 & 1.74 (1.14 to 2.65$)$ & 27 & 92 & 1.26 (0.59 to 2.68$)$ & 20 & 53 & 6.46 & (1.34 to 31.3 ) \\
\hline$\geq 14.62$ & 98 & 295 & 1.27 (0.82 to 1.98$)$ & 30 & 72 & 1.64 (0.69 to 3.88$)$ & 28 & 68 & 6.47 & (1.33 to 31.5 ) \\
\hline \multicolumn{11}{|l|}{ Linear term§ } \\
\hline RQ & 292 & 872 & 1.00 (0.98 to 1.02$)$ & 110 & 330 & 1.03 (0.99 to 1.07$)$ & 50 & 150 & 1.04 & (0.99 to 1.09 ) \\
\hline \multicolumn{11}{|l|}{ Log-linear term§ } \\
\hline $\operatorname{Ln}(1+R Q)$ & 292 & 872 & 1.11 (0.90 to 1.37$)$ & 110 & 330 & 1.23 (0.82 to 1.83$)$ & 50 & 150 & 1.97 & (1.05 to 3.71 ) \\
\hline
\end{tabular}

*Date of birth after 8 May 1929 .

tCrude analysis.

¥With adjustment for smoking and first erythrocyte sedimentation rate

$\S$ With additional adjustment for metabolic syndrome.

log- transformation, which yielded $\mathrm{OR}=1.97$ (95\%CI: 1.05 to 3.71) in the fully adjusted model.

The likelihood-ratio test confirms the significant impact of RQ on the AMI-risk, both for the model based on tertiles and for the model based on the log-transformed exposure. The comparison of both models by means of AIC is in favour of the categorical model. The ORs of the exposure were similar throughout all three models in the complete database as well as in the subgroups regardless of the respective covariates.

\section{DISCUSSION}

Given the complete study base, there is no statistically significant impact of occupational quartz dust on the first AMI. In contrast, the analysis restricted to the subgroup of late birth cohorts from subcohort A showed a significant risk increase. The decisive argument to highlight this subgroup is that it is virtually unaffected by unmeasured pre-exposure to RQ: Its subjects commenced employment at young age ( 19 years on average) in a period of very high occupational exposures and they stayed with the company for many years (31 years on average). However, this subgroup comprises only 50 matched sets, ie, $17 \%$ of the study population. Hence, our study adds to the still small body of evidence for an exposure-response relationship between RQ exposure and AMI risk.

A major strength of our study is that all potential study subjects were reviewed using medical records from the comprehensive GDAW archives.

This procedure largely ensures that only first events, but no reinfarcts, are included as cases in the study whereas potential controls with hints at previous AMI are excluded. In contrast, in mortality-based studies only the fatal AMI is observed. Thus, possible previous non-fatal AMI events, requiring a change of job with a respective decrease of exposure, could lead to a healthy-worker survivor bias. In order to minimise the risk of such a bias, we lagged the exposures by 5 years. The use of unlagged cumulative exposure leads virtually to the same results, since the cumulative exposure in the last 5 years is for almost all subjects negligible in comparison to the previous exposure (data not shown).

Reports of preventive medical examinations provided also important data on non-occupational cardiovascular risk factors. $^{23} 24$ We considered these risk factors as potential confounders or mediators in our models (tables 1 and 3, online supplementary tables S1, S2). We omitted the information on risk factors that only turned out within the 5 years ahead of the index date. However, the results with and without this lag time did not differ much (online supplementary table S2).

Interestingly, the RQ-related ORs showed similarities, regardless of the covariates introduced in the respective model (table 3). This suggests that smoking, baseline ESR and the metabolic syndrome, although very predictive for AMI, do not generally confound the estimation. The metabolic syndrome had been suspected to mediate the effect of RQ on AMI, but it did not, as the introduction of this covariate did not lower the RQ-related ORs, neither in the analysis of the complete database nor in the subgroups. Thus, the metabolic syndrome seems to be an independent risk factor for AMI.

We are aware of some weaknesses of our study. Underdetection of cases cannot be ruled out. This weakness is unavoidable as there is neither a national AMI registry nor a hospital discharge registry for Germany. Another source of underdetection of cases in this study could be the absence of emergency medical services until the mid-1960s. Until then, the proportion of severe AMI cases that died before reaching the hospital might have been much higher. Another weakness of our study is that RQ is not the only hazard uranium miners are exposed to. We had to ask whether a possible impact of $\mathrm{RQ}$ is not in truth an impact of ionising radiation. ${ }^{25}$ We thus used the study design to alternatively explore the impact of radon, gamma radiation and long-lived radionuclides on AMI. Despite strong correlations of all hazards mentioned, but in line with a previous study in the Wismut cohort, ${ }^{26}$ we found no effect (results not shown).

Different silica exposure levels should be addressed because differences in these levels between earlier and more recent 
cohort studies have been discussed as an explanation of the inconsistencies in literature. ${ }^{9}$

The present study reflects an exposure scenario in uranium ore mining based on data from 1946 to 1990 with very high annual RQ exposure, especially in the first decade (figure 2). Permissible limit values for RQ dust have been reduced substantially since. But silicosis is still among the 10 most frequent recognised occupational diseases in Germany. ${ }^{27}$ Even today the hazard of high occupational exposure to RQ is not averted. ${ }^{28} 29$

To conclude, although a significant risk increase was only seen in a small subgroup of our study, a link between RQ exposure and AMI could not be ruled out. Further investigations on this topic are desirable. Such a study requires a thorough validation of the outcome based on clinical data, as well as reliable exposure information on the subjects' complete occupational history.

Acknowledgements The authors wish to acknowledge: the Department of Radiation Protection and Health, Federal Office for Radiation Protection, for the provision of the exposure data; Annette Förster, Marie-Luise Rieß and Franca Stein for the ICD-10 coding of 114000 hospital discharge diagnoses; Ramona Ehlicke, Annett Müller, Roswitha Hänsch, Anett Seitz and Astrid Soja for data acquisition from the medical records; Lutz Bernhardt and Roland Scheibner for managing the database of the health data archives Wismut.

Contributors JG and MM conceived the research question. JG checked the medical records of all study subjects and verified all AMI diagnoses. DP supervised the data collection, programmed the study database and carried out quality controls. MM performed the statistical analysis. JG wrote the first draft of the manuscript. All authors revised it critically and approved the final version. MM is responsible for the overall content as guarantor.

Funding This work was done within the normal activities of all authors without any sponsoring.

Competing interests None declared.

Patient consent for publication Not required.

Ethics approval The data protection officer of the Federal Institute for Occupational Safety and Health and the Institutional Review Board approved the study design.

Provenance and peer review Not commissioned; externally peer reviewed.

Open access This is an open access article distributed in accordance with the Creative Commons Attribution Non Commercial (CC BY-NC 4.0) license, which permits others to distribute, remix, adapt, build upon this work non-commercially, and license their derivative works on different terms, provided the original work is properly cited, appropriate credit is given, any changes made indicated, and the use is non-commercial. See: http://creativecommons.org/licenses/by-nc/4.0/.

\section{REFERENCES}

1 Steenland K, Ward E. Silica: a lung carcinogen. CA Cancer J Clin 2014;64:63-9.

2 Möhner M, Kersten N, Gellissen J. Chronic obstructive pulmonary disease and longitudinal changes in pulmonary function due to occupational exposure to respirable quartz. Occup Environ Med 2013;70:9-14.

3 Weiner J, Barlow L, Sjögren B. Ischemic heart disease mortality among miners and other potentially silica-exposed workers. Am J Ind Med 2007;50:403-8.
4 Fang SC, Cassidy A, Christiani DC. A systematic review of occupational exposure to particulate matter and cardiovascular disease. Int I Environ Res Public Health 2010; 7:1773-806

5 Libby P, Ridker PM, Hansson GK, et al. Inflammation in atherosclerosis: from pathophysiology to practice. J Am Coll Cardiol 2009;54:2129-38.

6 Hansson GK. Inflammation, atherosclerosis, and coronary artery disease. N Engl J Med 2005;352:1685-95.

7 Andresdottir MB, Sigfusson N, Sigvaldason H, et al. Erythrocyte sedimentation rate, an independent predictor of coronary heart disease in men and women: The Reykjavik Study. Am J Epidemiol 2003;158:844-51.

8 Torén K, Bergdahl IA, Nilsson T, et al. Occupational exposure to particulate air pollution and mortality due to ischaemic heart disease and cerebrovascular disease. Occup Environ Med 2007:64:515-9.

9 Fan C, Graff P, Vihlborg P, et al. Silica exposure increases the risk of stroke but not myocardial infarction-A retrospective cohort study. PLoS One 2018;13:e0192840.

10 Sjögren B. Occupational exposure to dust: inflammation and ischaemic heart disease. Occup Environ Med 1997:54:466-9.

11 Hammar N, Alfredsson L, Smedberg M, et al. Differences in the incidence of myocardial infarction among occupational groups. Scand I Work Environ Health 1992;18:178-85.

12 Wyndham CH, Bezuidenhout BN, Greenacre MJ, et al. Mortality of middle aged white South African gold miners. Br J Ind Med 1986;43:677-84.

13 Reid PJ, Sluis-Cremer GK. Mortality of white South African gold miners. Occup Environ Med 1996:53:11-16

14 Kreuzer M, Grosche B, Dufey F, et al. The German Uranium Miners Cohort Study (Wismut cohort), 1946-2003. Oberschleissheim: Bundesamt für Strahlenschutz 2011:50.

15 Grosche B, Kreuzer M, Kreisheimer M, et al. Lung cancer risk among German male uranium miners: a cohort study, 1946-1998. Br J Cancer 2006;95:1280-7.

16 IDF. The IDF consensus worldwide definition of the metabolic syndrome. Brussels: IDF, 2006:24.

17 Alberti KG, Zimmet P, Shaw J. Metabolic syndrome--a new world-wide definition. A Consensus Statement from the International Diabetes Federation. Diabet Med 2006;23:469-80.

18 Dahmann D, Bauer HD, Stoyke G. Retrospective exposure assessment for respirable and inhalable dust, crystalline silica and arsenic in the former German uranium mines of SAG/SDAG Wismut. Int Arch Occup Environ Health 2008;81:949-58.

19 Runge W, ed. Chronik der Wismut. Chemnitz: Wismut GmbH, 1999.

20 Schlesselman JJ. Case-control studies. Design, conduct and analysis. New York: Oxford Univ Press, 1982:368.

21 StataCorp. Stata: Release 15. Statistical Software. College Station, TX: StataCorp LP, 2017.

22 Mente A, Yusuf S, Islam S, et al. Metabolic syndrome and risk of acute myocardial infarction a case-control study of 26,903 subjects from 52 countries. J Am Coll Cardiol 2010;55:2390-8

23 Anand SS, Islam S, Rosengren A, et al. Risk factors for myocardial infarction in women and men: insights from the INTERHEART study. Eur Heart J 2008;29:932-40.

24 Yusuf S, Hawken S, Ounpuu S, et al. Effect of potentially modifiable risk factors associated with myocardial infarction in 52 countries (the INTERHEART study): casecontrol study. Lancet 2004:364:937-52.

25 Darby SC, Ewertz M, McGale P, et al. Risk of ischemic heart disease in women after radiotherapy for breast cancer. N Engl J Med 2013;368:987-98.

26 Kreuzer M, Kreisheimer M, Kandel M, et al. Mortality from cardiovascular diseases in the German uranium miners cohort study, 1946-1998. Radiat Environ Biophys 2006:45:159-66.

27 DGUV. BK-Monitoring-Bericht Berufskrankheiten im Jahr 2016, 2018.

28 Laney AS, Attfield MD. Coal workers' pneumoconiosis and progressive massive fibrosis are increasingly more prevalent among workers in small underground coal mines in the United States. Occup Environ Med 2010:67:428-31.

29 Perret JL, Plush B, Lachapelle P, et al. Coal mine dust lung disease in the modern era. Respirology 2017;22:662-70. 